\title{
Use of complementary and alternative medicine in Danish hospitals as reported by charge nurses at department level
}

\author{
Lasse Skovgaard ${ }^{1,2}$, Søren la Cour ${ }^{1}$, Mette Kristensen ${ }^{1}$ \\ 1. KUFAB, University of Copenhagen, Institute of Sociology, Øster Farimagsgade, Copenhagen K, Denmark. \\ 2. Department of Public Health, University of Copenhagen, Øster Farimagsgade, Copenhagen K, Denmark.
}

Correspondence: Lasse Skovgaard. Address: KUFAB, University of Copenhagen, Institute of Sociology, Øster Farimagsgade 5, 1014 Copenhagen K, Denmark. E-mail: lesk@sund.ku.dk

Received: November 8, 2012

DOI : $10.5430 /$ jha.v2n2p22
Accepted: November 19, 2012

URL: http://dx.doi.org/10.5430/jha.v2n2p22

\section{Abstract}

This study has investigated the use of complementary and alternative medicine (CAM) at Danish hospitals as reported by department nurses. A questionnaire was sent to department nurses at 669 hospital departments, distributed among 130 hospitals. The study showed that CAM was offered at $20.6 \%$ of the hospital departments, distributed among $41.5 \%$ of the Danish hospitals. 23 different CAM modalities were reported in use of which acupuncture, massage and art therapy had highest prevalence. Studies that have shown effect and experienced effect within the department were most often reported as motives for offering CAM. Compared to a similar study with chief physicians as respondents, the prevalence of CAM in use in this way was slightly higher and the variation of CAM modalities in use was significantly higher.

\section{Key words}

Complementary and alternative medicine, Charge nurses, Alternative and complementary medicine, Denmark

\section{Background}

Use of complementary and alternative medicine (CAM) has increased markedly in the Western world over the past 20 years ${ }^{[1-3]}$ and units for integrated medicine (conventional medicine combined with CAM) are increasingly being established in healthcare systems in many countries ${ }^{[4-9]}$.

In Denmark, the proportion of the population that has used CAM, increased from $23 \%$ in 1987 to $52.8 \%$ in 2010 and in $201026.3 \%$ had used CAM within the past twelve months ${ }^{[10,11]}$. The typical user is female, aged 25-64 years and has 13-14 years of schooling as educational background. Massage, acupuncture and reflexology have been the most frequently used CAM modalities in recent years ${ }^{[10]}$.

Within health care systems an increase in the use of CAM can also be detected. A Danish-Norwegian study from 2008/2009 has investigated the use of CAM in Danish and Norwegian hospitals, as reported by chief physicians at hospital management level ${ }^{[12]}$. The study shows that the use of CAM is increasing in hospitals in both countries, and within the Danish hospital system particularly acupuncture has become popular in recent years ${ }^{[12,13]}$. 
A Swiss study from 2006 has shown that there may be discrepancies between the reporting of CAM use, depending on the level at which you ask ${ }^{[14]}$. The study reported a 33\% use of CAM in Swiss hospitals, based on responses from the hospital managements, while $37 \%$ of the hospitals reported use of CAM when they were asked at department level. At the department level a larger variety of CAM modalities was also reported.

As a supplement to the abovementioned Danish-Norwegian study, a questionnaire was sent to all charge nurses at department level in Danish hospitals. The purpose of this supplementary study was to examine how the overall use of CAM was reported by charge nurses at department level as well as examining whether the reporting of CAM usage varied depending on the organizational level of respondents.

\section{Methods}

The study involved both somatic and psychiatric hospitals as well as public and private hospitals that have arrangements with the public Danish health insurance.

Contact information of all charge nurses at Danish hospital departments was collected partly through Internet search and partly via telephone calls to the hospitals/hospital departments. Firstly, all departments were localized at each hospital and secondly the charge nurse at each department was localized. In some cases, one department was divided into several sections, each with a charge nurse affiliated. In these cases, charge nurses at the sectional level were also included as respondents.

The questionnaire was developed and validated in collaboration with researchers from The National Research Center in Complementary and Alternative Medicine (NAFKAM), University of Tromsø, Norway. In the questionnaire, a list of pre-defined CAM modalities was presented as well as room for information about additional modalities in use. Furthermore an open response category was included in the questionnaire, asking the respondents to specify the motives for CAM usage at the department.

The data collection started in June 2008 and ended in December 2008. Reminders were sent twice, after 2 months and after 4 months.

Data were collected through web-based questionnaires. A mail with a link to the questionnaire was sent to 669 department nurses, distributed among 130 hospitals. 461 questionnaires were answered, giving a response rate of 68.9\%.

Data have been collected in SurveyXact and processed in SPSS version 13.0. The study was designed to collect information on the overall use of CAM in Danish hospitals as reported by charge nurses at department level. Information on types of department and types of hospital have not been included in the data collection and hence not as variables in the analyses performed.

\section{Results}

\subsection{The use of CAM}

CAM was reported in use in $20.6 \%$ of the hospital departments, in $41.5 \%$ of the hospitals.

As shown in Table 1, 23 different CAM modalities were reported in use at Danish hospitals departments. Acupuncture, massage and art therapy were the CAM modalities most commonly being offered. Reflexology, Gestalt therapy, 
meditation, music therapy, ball cushion therapy, hypnosis, healing and mindfulness were offered at more than one department. In addition, a number of CAM modalities were offered at one department.

Table 1. CAM modalities offered at Danish hospital departments

\begin{tabular}{lll}
\hline \multirow{2}{*}{ Modality } & \multicolumn{2}{l}{ Hospital departments (n=95/461) } \\
\cline { 2 - 3 } & Number & \% \\
\hline Acupuncture & 65 & 68.4 \\
Massage & 22 & 23.2 \\
Art therapy & 15 & 15.8 \\
Meditation & 5 & 5.3 \\
Gestalt therapy & 4 & 4.2 \\
Music therapy & 4 & 4.2 \\
Reflexology & 2 & 2.1 \\
Healing & 2 & 2.1 \\
Ball cushion therapy & 2 & 2.1 \\
Hypnosis & 2 & 2.1 \\
Mindfulness & 2 & 2.1 \\
Herbal medicine & 1 & 1.1 \\
Alternative diet & 1 & 1.1 \\
Psycho drama & 1 & 1.1 \\
Thought field therapy & 1 & 1.1 \\
Body-touch & 1 & 1.1 \\
Breathing exercises & 1 & 1.1 \\
Hot compress & 1 & 1.1 \\
Use of maggots for wound cleansing & 1 & 1.1 \\
Glucosamine & 1 & 1.1 \\
Body therapy & 1 & 1.1 \\
NADA & 1 & 1.1 \\
Craniosacral therapy & 1 & 1.1 \\
\hline
\end{tabular}

\subsection{Motives / reasons for offering CAM}

In an open response category the respondents commented on motives and reasons for starting up the use of CAM. These responses have been thematized and are presented in Table 2 . The results show that the main motives were constituted by studies that have shown effect as well as the departments' own experiences with positive effect. The presence of employees with education within CAM, and the perception that CAM can offer something that conventional treatments cannot, were also mentioned as important motives.

The issue of defining CAM was mentioned by several departments, where respondents indicated that they did not perceive the CAM modality in use as alternative/complementary due to existing documentation and /or general acceptance. This argument was presented in relation to massage, acupuncture and meditation.

\section{Discussion}

\subsection{Chief physicians and department nurses as respondents}

The previously mentioned Swiss study from 2006 showed that the reported use of CAM, as well as the variety of treatment modalities used, was larger when reported at department level (37\%) than at hospital management level (33\%) ${ }^{[14]}$. A 
similar difference applies to Danish conditions; the Danish-Norwegian study found that CAM was used in 31\% of Danish hospitals, distributed among two CAM modalities, when the chief physicians at hospital management level were asked. However, massage was not included as a CAM modality in the Danish-Norwegian study ${ }^{[12]}$. If the use of massage is precluded from the current study, CAM is used in $33.8 \%$ of the Danish hospitals, represented by 23 different CAM modalities.

This difference in reporting can be regarded as peripheral in terms of the proportion of hospitals offering CAM (31\% vs. $33.8 \%$ ), but significant in terms of the variety of CAM modalities (2 vs. 23). The latter circumstance may have several explanations. One could imagine that the chief physicians are not familiar with all of the CAM treatments being performed at the individual departments. Either because this information has not reached the management level, or because it has been held back deliberately. One could also imagine that the chief physicians are familiar with the conditions, but that they do not want to confirm it in a survey. Further studies may elucidate this matter.

Table 2. Motives for offering CAM at Danish hospital departments

\begin{tabular}{|c|c|}
\hline Motives & Times mentioned \\
\hline Studies have shown effect & 13 \\
\hline Good experience with effect within the department & 12 \\
\hline CAM has something to offer, when the conventional methods are not sufficient & 8 \\
\hline The department has employees educated within CAM & 8 \\
\hline We have conventional educated health care staff to perform the CAM treatments & 7 \\
\hline Alternative treatment is a good supplement to conventional treatment & 6 \\
\hline The used alternative treatment modality is not considered alternative & 6 \\
\hline The patients' demand/request & 5 \\
\hline Inspiration/good experiences from other departments/hospitals & 3 \\
\hline Employees’ experiences/knowledge & 3 \\
\hline $\begin{array}{l}\text { Evidence is available for the used alternative treatment modality and the treatment is hence } \\
\text { not considered as alternative }\end{array}$ & 3 \\
\hline The patients use CAM and we should therefore incorporate this to accommodate them & 3 \\
\hline The holistic/individual approach of CAM is considered relevant & 3 \\
\hline Experience of shorter hospitalisation time, faster recovery/rehabilitation & 3 \\
\hline The experiences show general effect & 3 \\
\hline A wish to/experience of being able to reduce the use of medicine & 2 \\
\hline Articles and professional debates about the topic & 2 \\
\hline CAM does not imply side effects & 2 \\
\hline A wish for breadth in the offered treatments for the purpose of meeting complex issues & 1 \\
\hline General interest in CAM & 1 \\
\hline Openness from the management & 1 \\
\hline It is important to be open to new initiatives & 1 \\
\hline
\end{tabular}

\subsection{Are we moving towards integrated medicine?}

The results from this study can be seen as an indication that the increased interest in CAM among the Danish population is reflected within the Danish health care system. The extent and variety of CAM modalities being used in Danish hospital departments indicate an overall growing openness to non-conventional therapies. Whether this development can be seen as an indication of a trend toward the development of an integrated medicine cannot be concluded on the basis of this study, but must be assessed through comparative studies over time. 


\subsection{About the study}

Although it has not been possible to include information on types of department and types of hospital in the analyses, we believe that the current data present relevant information regarding the variation of CAM modalities generally in use in Danish hospitals. We believe that the difference between the variation of CAM modalities reported in use by chief physicians and by charge nurses presents in itself usefull information that point to the relevance of further studies.

\section{Acknowledgements}

The study was financially supported by ViFAB, Aarhus, Denmark.

\section{References}

[1] Frass M, Strassl RP, Friehs H, Mullner M, Kundi M, Kaye AD. Use and acceptance of complementary and alternative medicine among the general population and medical personnel: a systematic review. The Ochsner journal. 2012; 12(1): 45-56. Epub 2012/03/23.

[2] Hanssen B, Grimsgaard S, Launsø L, Fønnebø V, Falkenberg T, Rasmussen NK. Use of complementary and alternative medicine in the Scandinavian countries. Scand J Prim Health Care. 2005 Mar; 23(1): 57-62. PMid:16025876 http://dx.doi.org/10.1080/02813430510018419

[3] Barnes PM, Powell-Griner E, McFann K, Nahin RL. Complementary and Alternative Medicine Use Among Adults: United States, 2002. Advance Data from Vital and Health Statistics. 2004; 343.

[4] Launsø L. Integrated Medicine in Practice - a Challenge to the Health Care System. Acta Sociol. 1989; 32(3): $237-51$. http://dx.doi.org/10.1177/000169938903200303

[5] Mann D, Gaylord S, Norton S. Moving toward integrative treatment: Rationales, models, and steps for conventional-care providers. Complement Health Pract Rev. 2004; 9(3): 155-72.

[6] Mulkins AL, Verhoef MJ. Supporting the transformative process: experiences of cancer patients receiving integrative care. Integr Cancer Ther. 2004 Sep; 3(3): 230-7. PMid:15312264 http://dx.doi.org/10.1177/1534735404268054

[7] Gamst A, Haahr N, Kristoffersen AE, Launsø L. Integrative care and bridge building among health care providers in Norway and Denmark. J Altern Complement Med. 2006 Mar; 12(2): 141-6. PMid:16566673 http://dx.doi.org/10.1089/acm.2006.12.141

[8] Launsø L, Haahr N. Bridge Building and Integrative Treatment of People with Multiple Sclerosis. Research-based Evaluation of a Team-building Process. J Complement Integr Med. 2007; 4(1). http://dx.doi.org/10.2202/1553-3840.1046

[9] Scherwitz LW, Cantwell M, McHenry P, Wood C, Stewart W. A descriptive analysis of an integrative medicine clinic. J Altern Complement Med. 2004 Aug; 10(4): 651-9. PMid:15353021

[10] Christensen AI, Ekholm O, Davidsen M, Juel K. Sundhed og sygelighed i Danmark 2010. [Health and disease in Denmark 2012]. Statens Institut for Folkesundhed, Syddansk Universitet 2012.

[11] Rasmussen NK, Groth SR, Bredkjær SR, Madsen M, Kamper-Jørgensen F. Sundhed og sygelighed i Danmark 1987. En rapport fra DIKEs undersøgelse. [Health and disease in Denmark 1987. A report from the investigation of DIKE]. København: DIKE; 1988.

[12] Salomonsen LJ, Skovgaard L, la Cour S, Nyborg L, Launsø L, Fønnebø V. Use of Complementary and alternative medicine (CAM) in Norwegian and Danish hospitals. BMC Complement Altern Med. 2011; 11: 4. PMid:21244655

http://dx.doi.org/10.1186/1472-6882-11-4

[13] Videns- og forskningscenter for alternativ behandling (ViFAB). Stigende brug af akupunktur på danske sygehuse [Internet]. Available from: http://www vifab dk/nyheder/nyheder+2009/stigende+brug+af+akupunktur+p\%C3\%A5+danske+sygehuse 2010 March 10

[14] Widmer M, Donges A, Wapf V, Busato A, Herren S. The supply of complementary and alternative medicine in Swiss hospitals. Forsch Komplementmed. 2006 Dec; 13(6): 356-61. PMid:17200610 http://dx.doi.org/10.1159/000097254 